\title{
Oak Bark (Quercus sp. cortex) Protects Plants Through the Inhibition of Quorum Sensing Mediated Virulence of Pectobacterium carotovorum
}

\author{
Alexey S Vasilchenko ( $\square$ avasilchenko@gmail.com ) \\ Orenburg state universuty https://orcid.org/0000-0001-9970-4881
}

\section{Darya Poshvina}

Tyumen State University: Tumenskij gosudarstvennyj universitet

\section{Roman Sidorov}

Institute of Ecology and Genetics of Microorganisms UB RAS: Institut ekologii i genetiki

mikroorganizmov UrO RAN

\section{Aleksandr lashnikov}

Tyumen State University: Tumenskij gosudarstvennyj universitet

\section{Eugene A Rogozhin}

Shemyakin-Ovchinnikov Institute of Bioorganic Chemistry Russian Academy of Sciences: FBGUN Institut bioorganiceskoj himii im akademikov M M Semakina i U A Ovcinnikova Rossijskoj akademii nauk Anastasia Vasilchenko

Tyumen State University: Tumenskij gosudarstvennyj universitet

\section{Research Article}

Keywords: Pectobacterium carotovorum, soft-rot disease, quorum sensing, quorum quenching, oak bark extract, plant-derived molecules, Quercus sp

Posted Date: February 23rd, 2022

DOI: https://doi.org/10.21203/rs.3.rs-1360881/v1

License: (c) (i) This work is licensed under a Creative Commons Attribution 4.0 International License. Read Full License 


\section{Abstract}

Bacterial intercellular communication mediated by small diffusible molecules, known as quorum sensing (QS), is a common mechanism for regulating bacterial colonisation strategies and survival. Influence on QS by plant-derived molecules is proposed as a strategy for combating phytopathogens by modulating their virulence. This work builds upon other studies that have revealed plant-derived QS inhibitors extracted from oak bark (Quercus sp.). It was found that co-incubation of Pectobacterium carotovorum VKM-B-1247 with oak bark extract (OBE) reduced the production of acyl-HSL. This was accompanied by a dose-dependent decrease in the bacterial cellulolytic and protease activity. The effect of OBE treatment at the transcriptomic level is the suppression of the main QS-related genes expR/ expl. Potato tubers pretreated with OBE showed resistance to a manifestation of soft-rot symptoms. Analysis of the component composition of the OBE identified several biologically active molecules, such as n-hexadecanoic acid, 2,6di-tert-butyl-4-methylphenol, butylated hydroxytoluene (BHT), gamma-sitosterol, lupeol, and others. Molecular docking of the binding energy of the identified molecules with homology models of LuxR-LuxI type proteins showed high potential binding of a few plant-derived molecules to these proteins.

\section{Introduction}

Plant diseases of microbial aetiology are a serious threat to human biosafety around the globe. Until recently, it was believed that bacteria, as a cause of spoilage of agricultural products, cause relatively less economic damage comparing to fungi and viruses (Sundin et. al. 2016) However, the situation changes every year, and the importance of bacteriosis and the attention of agronomists to has increased. There has been an increase in plant infections caused by Pseudomonas syringae, Xanthomonas translucens, Pectobacterium sp., Xanthomonas sp., Clavibacter michiganensis, and Ralstonia solanacearum (Leadbeater et. al. 2014).

Good agricultural practices, cultivation and crop rotation are important tools to minimize the impact of pathogenic bacteria on crops. However, these measures do not lead to complete success, and bacterial diseases of crops are found to be difficult to control. At present, the situation is such that there are almost no effective tools means to protect plants from bacterioses. If the list of fungicides contains hundreds of preparations, then a number of antibacterial drugs is limited to copper compounds in combination with fungicides, less often, these can be antibiotics aminoglycosides or tetracyclines used to treat fruit trees in some countries (Leadbeater et. al. 2014). In addition, the usage of chemical pesticides and antibiotics often leads to the development of field resistance (Travis et. al. 2012). Thus, it is necessary to search for new bactericidal substances with a new mechanism of antimicrobial action to overcome resistant forms which already exist.

The phenomenon of density-dependent intercellular communication of bacteria by chemical molecules known as quorum sensing (QS), was discovered at the end of the 20th century (Fuqua et. al. 1994). This finding made it possible to look differently at the functioning of microbial communities, including how the pathogenic potential of a bacterial population is realised. Moreover, it became clear that dissociation 
of intercellular communication could appear a promising approach to fighting infections, as long as cells remain alive, which means that the selective pressure on the population decreases, and the selection of resistant forms is unlikely (Ji et. al. 2014). The suppression of the QS system functionality of some organisms by others is widespread in nature and called quorum quenching (Grandclément, et. al. 2016).

In addition to bactericidal substances, for self-defence plants synthesise many different low molecular weight molecules that suppress the functioning of the QS system of phytopathogens (Koh et. al. 2013, Deryabin et al 2019, Janak et. al. 2021). The inhibition of QS is realised by various mechanisms, including enzymatic degradation, adsorption on various macromolecules, and interference with the production or perception of autoinducers (Als) (Grandclément et. al. 2016). Quorum quenchers of plant origin implement their own action through interference with the perception and biosynthesis of QS Als (Koh et. al. 2013, Deryabin et. al. 2019, Janak et. al. 2021). Since numerous plant-derived molecules have structural similarities to natural Als, this allows them to competes for Al binding sites. Thus, several chemical classes of molecules related to terpenes, phenylpropanoids, flavonoids, tannins, and ellagitannins bind and disturb the functionality of LuxR/l-type receptor proteins (Deryabin et. al. 2019).

Pectobacterium carotovorum is a Gram-negative bacterium that is widespread throughout the world. The ability to produce a number of plant cell wall degrading enzymes (PCWDEs) including pectinases, cellulases, and proteases (Põllumaa et. al. 2012) determines the presence of this species in the list of top10 phytopathogenic microorganisms (Mansfield et. al. 2012). P. carotovorum responsible for causing soft-rot in numerous types of plants, including economically important potato crop (Solanum tuberosum).

The production of PCWDEs is triggered by a quorum-dependent mechanism when conditions for cell growth are favourable and there is a high requirement for nutrients and habitat expansion (Põllumaa et. al. 2012). The functioning of the QS system of $P$. carotovorum based on biosynthesis of acylated homoserine lactones (C6-0xo-HSL or C8-0xo-HSL) and the perception of them by ExpR receptor proteins (Põllumaa et. al. 2012). Several studies have demonstrated the effectiveness of plant-derived substances as a quorum quencher to prevent plant diseases caused by Pectobacterium sp. strains (Janak et. al. 2020, Pun et. al. 2021).

Previously, suppression effects of extracts derived from tissues of Quercus virginiana Mill (Fagaceae) (Adonizio et. al. 2021) and Quercus robur (Tolmacheva et. al. 2014) were shown against the QS system of Chromobacterium violaceum. However, the details of this phenomenon are still unknown.

In this work, we describe the chain of events from the moment of contact of the phytopathogen with plant molecules (Quercus sp.), and the possibility of using the revealed QS-inhibitory phenomenon in plant protection. We studied the effects of OBE on the expression of the main QS-related genes and the manifestation of QS-dependent virulence in vitro and in vivo. Using gas chromatography coupled with to mass spectrometry and molecular docking analysis, we described the molecular composition of OBE and identified the most likely inhibitors. 


\section{Material And Methods \\ 2.1 Bacterial strains}

Pectobacterium carotovorum (Jones) Waldee VKM B-1247 was obtained from the All-Russian Collection of Microorganisms (Pushchino, Russia). This strain produces 3-oxohexanoyl-L-homoserine lactone (3oxo-C6- HSL) as it was revealed by HPLC-MS method (Figure S5).

Chromobacterium violaceum CV 026 is a mini-Tn5 mutant of wild type ATCC 31532, deficient in QS dependent violacein production was used as a biosensor for detecting exogenous acyl- HSL. $C$. violaceium CV026 produces purple pigment in response to short chain acyl- HSL.

Bioluminescent biosensors strain of Escherichia coli MG 1655 pVFR1-lux is a bioluminescence-based QSbiosensor (Manukhov, et. al. 2011). This strain carries the plasmid pVFR1, which possesses the IUXRI':IUXCDABE (meaning Iux/mutated) bioluminescent reporter gene. This system can detect acyl- HSL with acyl chains ranging from six to twelve carbons in length (C6 to C12 acyl-HSLs).

\subsection{Extract preparation}

Pharmacological preparation of oak bark (registrational number N001007/01) produced by pharmacological company "Farmatsvet" (Russia) has been used in this work. The preparation formulated as a chopped oak bark of Quercus sp. plants which were collected in Krasnodar region of Russia in August 2020.

Extract from oak bark was prepared by extraction with an organic solvent. A weighted portion of $10 \mathrm{~g}$ of oak bark was poured into $100 \mathrm{ml}$ of $70 \%$ ethanol $(\mathrm{v} / \mathrm{v})$, and stirred for an hour at $25 \mathrm{C}$. The resulting suspension was centrifuged at $9000 \mathrm{rpm}$ for $15 \mathrm{~min}$, and then supernatant was filtered through a filtration system $(0.22 \mu \mathrm{m}$ pore diameter). The resulting solution was frozen in liquid nitrogen and lyophilized.

\subsection{Gas-MS-chromatography of Oak bark extract}

Chromato-mass spectrometric study was carried out on a Trace GC Ultra chromatograph with a DSQ II mass-selective detector in the electron ionization mode $(70 \mathrm{eV})$. Thermo TR-5 MS quartz capillary column $15 \mathrm{~m}$ long, $0.25 \mathrm{~mm}$ inner diameter, with a stationary phase film thickness of $0.25 \mu \mathrm{m}$ was used. Split-free input mode was used. Helium gas was used as the carrier gas at a constant flow rate of $1 \mathrm{~mL} / \mathrm{min}$. Evaporator temperature $250^{\circ} \mathrm{C}$, junction chamber temperature $250^{\circ} \mathrm{C}$, ion source temperature $250^{\circ} \mathrm{C}$. The temperature of the column thermostat was changed according to the program: from 80 (delay $5 \mathrm{~min}$ ) to $290^{\circ} \mathrm{C}$ at a rate of $15^{\circ} \mathrm{C} / \mathrm{min}$. The total analysis time is 29 minutes. The volume of the injected sample is $10.0 \mu$ l. Chromatograms were recorded in TIC mode. Mass scanning range 40-500 amu.

\subsection{Growth curves}


Pectobacterium carotovorum VKM-B-1247 was grown overnight at $28^{\circ} \mathrm{C}$ in $4 \mathrm{~mL}$ liquid medium under continuous shaking at $150 \mathrm{rpm}$. Prepared bacteria for $10^{6} \mathrm{CFU} / \mathrm{ml}$ subsequently have been inoculated to 96-well microtiter plates (Eppendorf, USA) containing growth media and various concentrations of oak bark extract in series of two-fold dilutions. The dynamics of bacterial growth were assessed by reading and plotting the absorbance data at $620 \mathrm{~nm}$ obtained by the spectrophotometer Multiscan GO (Thermo Scientific, USA).

\subsection{Qualitative determination of acyl-HSL formed by $P$. carotovorum under the influence of oak bark extract}

The overnight grown $P$. carotovorum culture was seeded on soft agarose LB-medium $(0.75 \% \mathrm{v} / \mathrm{v})$ supplemented with Oak bark extract $(0.5$ and $1.0 \mathrm{mg} / \mathrm{mL})$. P. carotovorum was checked for acyl-HSL production by striking against biosensor strain $C$. violaceium CV026 on soft agarose medium. The plates were incubated at $28^{\circ} \mathrm{C}$ for $24 \mathrm{~h}$ and acyl-AHL-dependent pigment production in CV026 was observed. The extent of purple pigment production in CV026 was indicative of diffusible acyl-AHL produced by $P$. carotovorum.

\subsection{Quantification of acyl-HSL formed by P. carotovorum under the influence of oak bark extract}

P. carotovorum was cultured in a volume of $10 \mathrm{~mL}$ in LB medium (tryptone -10 , yeast extract -10 , glucose $-0.5 \%, \mathrm{NaCl}-2 \mathrm{~g} / \mathrm{L}$ ) at $28 \mathrm{C}, 95 \mathrm{rpm}$. Upon reaching the stage of the exponential growth, $100 \mu \mathrm{l}$ of oak bark extract dilutions were added to the cells up to the final appropriate concentrations. The cells were subsequently cultured.

At hourly intervals, $1.5 \mathrm{ml}$ of each cell suspension was collected. Bacteria were precipitated by centrifugation at $10000 \mathrm{rpm} / 15 \mathrm{~min}, 6^{\circ} \mathrm{C}$. The supernatant was transferred into a separate tube for the quantitative analysis of autoinducers using the bioluminescence assay. Bacterial biomass was frozen in liquid nitrogen and stored at $-80^{\circ} \mathrm{C}$ for subsequent isolation of nucleic acids.

\subsection{Bioluminescence assay}

Quantitative detection acyl-HSL using biosensor E.coli MG1655 pVFR1-Iux

Supernatants of $P$. carotovorum cultures were mixed with biosensor $E$. coli MG 1655 pVFR1-lux in 96-well microtiter plates to a final volume of $100 \mu \mathrm{L}$. Bioluminescence was recorded as relative light units (RLU) using Multiscan FL reader (Thermo, USA) every $5 \mathrm{~min}$ at $25^{\circ} \mathrm{C}$. The resulting values of bioluminescence were estimated in induction factor $(\mathrm{R})$, which was processed according to the following Eq. 1:

$R=I t_{120 \min }-I t_{0 \min } / I c_{120 \min }-I c_{0 \text { min }}(1)$

Where $I t$ is intensity of bioluminescence of a treated sample; Ic is intensity of bioluminescence of the control sample (in the absence of inductor). 


\subsection{RNA sample collection and gene expression analysis using reverse transcription and quantitative Real-Time PCR (RT-qPCR).}

\section{RNA extraction and cDNA preparation}

Total RNA was isolated using the Quick-RNA Microprep kit (Zymo Research) according to the manufacturer's instruction. RNA was quantified using Qubit RNA HS Assay Kit (Thermo Fisher Scientific). Total RNA was further treated with DNase I (New England Biolabs) followed by the RNA Clean \& Concentrator-5 kit (Zymo Research). The absence of contaminating DNA was verified by PCR. Then, using the reverse transcription reaction, complementary DNA was obtained using the iScript reverse transcription supermix for RT-qPCR reagent (Bio-Rad, USA).

\section{Quantification of mRNA by quantitative real-time PCR (qRT-PCR)}

Quantitative PCR was carried out with the obtained cDNA using SsoAdvanced Universal SYBR Green Supermix (Bio-Rad, USA). Each reaction mixes with a volume of $20 \mu \mathrm{l}$ was prepared with $300 \mathrm{nM}$ each primer (final concentration) and 20 ng of cDNA. Light Cycler96 Real-Time PCR detection system (Roche, Switzerland) was used for the measurements using a protocol with the following thermal cycling conditions: DNA denaturation at $95{ }^{\circ} \mathrm{C}$ for $2 \mathrm{~min}$, followed by 40 cycles of denaturation at $95{ }^{\circ} \mathrm{C}$ for $10 \mathrm{~s}$ and annealing/extension at $60 \circ \mathrm{C}$ for $15 \mathrm{~s}$. After the last amplification cycle, a melting curve analysis was carried out by heating from 65 to $95^{\circ} \mathrm{C}$ in increments of $0.5^{\circ} \mathrm{C} / \mathrm{s}$. Negative controls (without template or reverse transcriptase enzyme) were included in each run. Gene-specific primers (described in Table S1) for the genes used in RT-qPCR experiments were designed using online service Integrated DNA technologies (https://www.idtdna.com/Primerquest/Home/Index). Fold changes in the expression levels of the investigated genes were normalized in relation to the levels of the housekeeping genes rho and recA mRNA.

\subsection{Effect of oak bark extract on production of plant cell wall degrading enzymes (PCWDEs)}

Semi-quantitative assays for protease and cellulase activities were performed using a plate assay. Protease activity was assessed by cultivation of bacteria on LB- medium (BD, USA) with $3 \%$ gelatin and $1 \%$ agar (w/w). Bacteria let grow for 24 hours, then Petri dishes were filled with ammonium sulfate solution to contrasting halo areas around colonies (Pitt, et. al. 1970).

Cellulase activity was assessed as described by Gupta et al (Pratima et. al. 2012). Bacteria seeded on medium contained $0.2 \%$ carboxymethyl cellulose and $25 \mathrm{mM}$ sodium phosphate, $0.75 \%$ agarose, CongoRed $0.02 \%$, and gelatin $0.2 \%(\mathrm{pH} 7.0)$. P. carotovorum was inoculated to the medium, and the plates were incubated at $28 \mathrm{C}$ for $48 \mathrm{~h}$. Cellulose-degrading potential was qualitatively estimated by calculating hydrolysis capacity, that is the ratio of diameter of halo zone and colony. 


\subsection{Effect of oak extract on virulence of $P$. carotovorum by potato maceration assay}

Assay based on methodic described in Singh et al. with our modifications (Singh, A.A., et. al. 2021). Potato tubers were purchased from the market and washed under tap water. The potato slices $(\sim 0.5 \mathrm{~cm})$ were surface sterilized by treating with $3 \%$ hydrogen peroxide for 30 minutes followed by washing with sterile distilled water. Each slice was placed in a sterile Petri plate containing wet filter paper. Prepared water suspension of the oak bark extract $(1 \mathrm{mg} / \mathrm{mL}$ ) or sterile water (control group) were scattered to the surface of potato slices and dried in the air. Bacterial suspension at $10^{6} \mathrm{CFU} / \mathrm{mL}$ was dropped at the center of each slice. The Petry dishes were incubated at $28 \mathrm{C}$ for 76 hours.

\subsection{In silico analysis}

Homology modeling of Cvil/CviR of Chromobacterium violaceum

Homology model of acyl-homoserine-lactone synthase Cvil of $C$. violaceum is based on its UniProt sequence (Q83XU6) and crystal structure of the homologous protein Tofl from Burkholderia glumae (PDB ID: $3 \mathrm{P} 2 \mathrm{H}$ ), which has endogenous ligand 5'-deoxy-5'-methylthioadenosine resolved in the catalytic site (Chung et. al. 2011) and shares $26 \%$ of identity with the target. These values are above the $20 \%$ threshold considered to be appropriate for homology modeling (Joshi et. al. 2016).

The 3D homology model of Cvil was built using Prime in Schrödinger Suite (Schrödinger, Inc., USA), sequences were aligned with Prime STA. Protein Reliability Report tool was utilized to assess binding pocket stability revealing no deviations from acceptable values.

CviR is a transcriptional regulator of Chromobacterium violaceum which structure was downloaded from the RCSB website (PDB ID: 3QP5) in the form of crystal structure bound to antagonist chlorolactone (Chen, et. al. 2011). The protein structures were prepared using the Protein Preparation Wizard implemented in Maestro.

\section{Docking}

The ligand structures were downloaded from the PubChem website. LigPrep tool was utilized to prepare ligands using the OPLS3 force field generating low energy ionized and tautomeric states at $\mathrm{pH} 7.0 \pm 2.0$, while chirality was determined from ligands 3D structure. Receptor grid box was centered using cocrystallized ligands and extended to $12 \AA$. Bound ligands were extracted and then was re-docked along with a set of optimized ligands of interest using Glide XP. Docking scores are demonstrated in the results section.

\subsection{Statistical analysis}


The experiments were performed using two independent series with 3 to 10 technical replicates each. The obtained results were statistically manipulated with Origin 2018 (OriginLab Corporation, Northampton, Massachusetts, USA) software.

The Shapiro-Wilk test was used to assess the normal distribution of values. In the presence of a normal distribution, the Student's t-test has been used, indicating the mean and standard deviation (Mean \pm SD). Differences were considered significant at $p$-value $\leq 0.05$.

\section{Results}

\subsection{Antibacterial effect of oak bark extract, and Its influence on biosynthesis of acyl-homoserine lactone}

First, the oak bark extract (OBE) was evaluated for its antimicrobial properties. We were unable to detect the inhibition of $P$. carotovorum cells growth by OBE taken at concentrations of $0.25-1.0 \mathrm{mg} / \mathrm{mL}$ (Figure S1).

In the second step, we assessed the OBE quorum quenching activity. The growth of $P$. carotovorum is accompanied by the diffusion of C6-oxo-HSL Als, which are perceived by the sensory strain Chromobacterium violaceum CV026 (Fig. 1). It has been shown that pectobateria produces less Als when growing on a medium containing OBE compared to a medium without any supplements (Fig. 1).

Thus, a qualitative suppression of the production of $P$. carotovorum Als by OBE was established, and the range of effective concentrations was determined. The quantitative effect of the addition of OBE on AI production was assessed using the bioluminescent strain of E. colipVFR1-lux. The induction of bioluminescence is proportional to the inducer concentration in the medium. It was found that $\mathrm{OBE}$ inhibited the biosynthesis of C6-oxo-HSL in dose-dependent manner. The inhibition effect was most pronounced when adding OBE at a concentration of $1 \mathrm{mg} / \mathrm{mL}$, this concentration delayed Als biosynthesis by $86 \%$ (Fig. 2). At the same time, no suppression of the viability of bacterial cells was observed (Figure S2).

\subsection{Expression of quorum sensing-regulated genes in the presence of oak bark extract}

The effect of the extract at the molecular level was assessed using quantitative PCR, targeting the main regulatory genes of the QS system. It was found that the expression of exp/and expR genes was affected under the influence of OBE. The most significant dysregulation was shown for the exp/gene (Fig. 3a). Coincubation of $P$. carotovorum with $0.5 \mathrm{mg} / \mathrm{mL}$ of OBE for 2 hours did not lead to a decrease in exp/ expression compared to the control, but $1.0 \mathrm{mg} / \mathrm{mL}$ was able to reduce gene expression. During the third hour of treatment, exp/ expression was significantly decreased at all tested concentrations, compared with the intact sample. In contrast, the transcription level of the expR gene in the intact samples had no changes over time, but under the treatment $(0.5$ and $1.0 \mathrm{mg} / \mathrm{mL}$ ) were decreased (Fig. 3b). 


\subsection{Effect of oak bark extract on the production of cell wall degrading enzymes}

The used strain of $P$. carotovorum VKM-B-1247 was tested for its ability to produce various enzymes involved in the degradation of plant tissues. The inhibition of protease and cellulase activity was found at all concentrations of OBE (Fig. 4). The virulence factor that was the most affected by the treatment was the protease activity. Thus, the addition of $0.5 \mathrm{mg} / \mathrm{mL}$ of OBE reduced the protease activity of pectobacterium by $50 \%$, while $1.0 \mathrm{mg} / \mathrm{mL}$ of OBE reduced the protease activity of pectobacterium by more than $90 \%$. At the same time, the cellulase activity was reduced by $60 \%$ in response to $1.0 \mathrm{mg} / \mathrm{mL}$ OBE in comparison with the intact control.

\subsection{Effect of oak bark extract on $P$. carotovorum virulence}

It is expected that a decrease in the biosynthesis of C6-oxo-HSL leads to a reduction in PCWDE activity and, in turn, to a decrease in the manifestations of the disease caused by P. carotovorum. To assess this, we infected the potato tuber with a suspension of $P$. carotovorum.

It turned out that the pre-treatment of potato tubers with OBE slowed down the development of symptoms of tissue maceration, compared with the control group. So, on the first day on the untreated potato slices signs of maceration appeared (Fig. 5a). After 72 hours, the mass of diseased tissue was about $20 \%$ of the mass of the whole potato (Fig. $5 \mathrm{~g}$ ). In turn, the blackening of the tissues of potatoes treated with OBE was not observed even by the third day of incubation (Figs. $5 d-f$ ), and the percentage of affected tissue remained less than $10 \%$ (Fig. $5 \mathrm{~g}$ ).

\subsection{Gas chromatography mass spectrometry (GC-MS) analysis of oak bark extract}

Gas chromatographic analysis of the oak bark extract allowed us to obtain mass spectra for 11 different substances with varying degrees of homology according to the NIST reference database (Table 1, Figure S3).

Among the identified components, the main part presented by lipophilic polyphenolic substance 2,2'methylenebis(6-tert-butyl-4-methylphenol) (relative content 21.3\%), n-hexadecanoic acid (8.6\%), plant phytosteroid gamma-sitosterol (4.3\%), terpenoid friedelan-3-one (3.4\%), phenolic antioxidant 2,6-di-tertbutyl-4-methylphenol (3.3\%), (5), pentacyclic triterpenoid lupeol (3.2\%), 1-(5-(hydroxymethyl)-2,2-dimethyl-

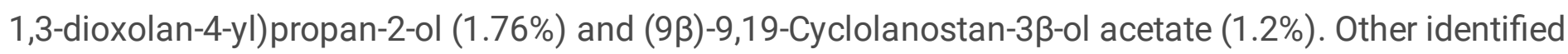
components presented in insignificant amounts $(<1 \%)$.

\subsection{Molecular docking analysis}

The mechanism determining the suppression of QS-dependent bacterial virulence must be sought in the intermolecular interaction of small molecules with the main components of the QS system. There are two crucial components in QS system: acyl-HSL producing enzymes and LuxR-type signal receptors (Chen, G., 
et. al. 2011). We used molecular docking to assess the binding capacity of the identified molecules (Table 2) to the active sites of these proteins.

Molecular docking of various ligands with LuxR-Luxl proteins requires their resolved crystal structures. However, only the structure of LuxR-type protein CviR is presented in Protein Data Bank (PDB ID: 3QP5). Considering the ability of oak bark extract to inhibit QS-dependent violacein biosynthesis in Chromobacterium violaceum ATCC 31532 (Figure S4), we performed in silico analysis using available structure CviR and generated homology model Cvil.

Cvil acyl-homoserine-lactone synthase homology model was built on the crystal structure of the homologous protein TofI (PDB ID: 3P2H) analogous to the previously described approach [26]. Using homology modelling, we calculated the active site composition of $C$. violaceum Cvil acyl-homoserinelactone synthase to provide a model for testing acyl-HSL producing enzyme inhibitors. Gamma-sitosterol demonstrated a slightly lower docking score $(-6.888 \mathrm{kcal} / \mathrm{mol})$ compared to the reaction by-product 5 'deoxy-5'-methylthioadenosine $(-7.553 \mathrm{kcal} / \mathrm{mol})$, which was resolved in the Tofl crystal structure and redocked to the Cvil homology model (Fig. 6a,b). Other candidates for potential acyl-HSL producing

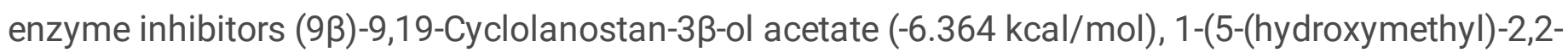
dimethyl-1,3-dioxolan-4-yl)propan-2-ol (-6.296 kcal/mol), 2,2'-methylenebis(4-methyl-6-tert-butylphenol) $(-5.835 \mathrm{kcal} / \mathrm{mol})($ Table 2$)$.

The $C$. violaceum CviR transcriptional regulator was analysed to model LuxR-type signal receptors. The best binding poses for every compound are shown in Table 2 . According to our predictive model for the CviR transcriptional regulator, 2,2'-methylenebis(4-methyl-6-tert-butylphenol) (Fig. 6d) and 1-(5(hydroxymethyl)-2,2-dimethyl-1,3-dioxolan-4-yl)propan-2-ol have slightly higher binding energy (-7.876 and $-7.739 \mathrm{kcal} / \mathrm{mol}$, respectively) than the known inhibitor chlorolactone $(-7.222 \mathrm{kcal} / \mathrm{mol})(\mathrm{Fig} .6 \mathrm{c})$ and thus can be analysed as potential QS signal blockers. 2,2'-Methylenebis(4-methyl-6-tert-butylphenol) and 1-(5-(hydroxymethyl)-2,2-dimethyl-1,3-dioxolan-4-yl)propan-2-ol bind several amino acids that play role in the chlorolactone interaction with the protein (Trp84, Tyr88, Asp97, Ser155) (Fig. 6d), therefore, a similar mechanism can be proposed. Docking analysis revealed that several compounds in OBE can possibly affect the functioning of both acyl-HSL producing enzymes and LuxRtype signal receptors.

\section{Discussion}

This work is a continuation of a series of studies devoted to discover and structure-functional analysis of plant-derived substances with quorum quenching activity. The bark and leaves of some oaks (Querqus spp.) are recognised pharmacological agents used in various countries for the treatment and prevention of infectious processes caused by viruses, bacteria, fungi, and other pathogens (Assessment report EMA/HMPC/3206/2009).

Regarding bacteria, the oak bark extract (OBE) is well known as a substance with bactericidal and bacteriostatic properties, while its quorum quenching activity was discovered recently (Adonizio et. al. 2006). Subsequently works in this direction have revealed details on the molecular composition of OBE 
which determine its quorum quenching properties (Deryabin et. al. 2015). However, the molecular details on how quorum quenching is realised is still unknown, and how it could be useful to fight microbial virulence is an ongoing research topic.

We estimated what extract of oak bark is potentially be considered as natural active substance to prevent plant disease caused by $P$. carotovorum. Interestingly, we found that the direct antimicrobial activity of $\mathrm{OBE}$ against $C$. violaceum and $P$. carotovorum is weak. In contrast, the anti-quorum activity of the $\mathrm{OBE}$ was pronounced against $C$. violaceum, as well as $P$. carotovorum. This is not surprising, given that the QS system of $P$. carotovorum, like $C$. violaceum, is arranged as the Luxl-LuxR regulatory system.

At the next stage, we carried out a quantitative assessment of the ability of oak bark extract to suppress the functioning of quorum sensing of pectobacteria. It turned out that co-incubation of the test strain with the studied drug inhibited the biosynthesis of QS-autoinducers. The implementation of suppression begins from the first hour and reaches a maximum by the third hour of exposure.

The mechanism of blocking quorum sensing was investigated at the transcriptomic and phenotypic levels. It turned out that oak bark extract reduces the expression of $\exp R$ and $\operatorname{expl}$, the products of which are proteins of reception and synthesis of acylhomoserine lactones, respectively.

Thus, oak bark extract affects the expression of QS-related genes, that led to reducing biosynthesis of Als and subsequently affects enzymatic activity of cellulases and proteases. In the ecology of pectobacteria, the processes of colonization of plant tissues are under the control of the QS system. After fixing on the surface of plants, pectobacteria produce various enzymes that destroy plant tissues. Therefore, the production of cellulases, pectinases and glycosyl hydrolases allows plant pathogenic bacteria to destroy the cell wall firstly, which provides the bacterial population with carbohydrates and allows it to penetrate inside plant tissues (Gorshkov et. al. 2017). In turn, proteases of phytopathogens destroy lectins, deactivate PR-proteins, mitogen-activated protein kinase (MAPK) and activate plant immunity and extensins that strengthen the structural integrity of the plant cell wall (Dow et. al. 1998; Savidor et al., 2012; Ek-Ramos et al., 2019; Gur-Arie et al., 2020).

Analysing the molecular composition of the oak bark extract, we used the method of gas chromatography with mass spectrometric detection. This method has proven itself well in the study of the chemical composition of various plant extracts (Husain et. al. 2017) including oak bark extract (Deryabin et. al. 2015). We found that none of the substances we identified had previously been found in the composition of the oak bark extract. The oak bark extract obtained in the work of Deryabin et. al. (2015) contained at least five different QS inhibitors, including vanillin, and coumarin derivatives. These molecules were not found in our samples. This result can be explained by two main reasons: first of all, an origin of biological material and composition of bark which admittedly belongs to different Querqus spp. (for instance, Q. robur and Q. pubescens); secondly, in this work we made soft trial preparation excepting high pressure and temperature during autoclaving that may lead to partial chemical degradation of components located inside the bark. 
Nevertheless, a number of identified molecules can potentially act as inhibitors of quorum sensing. It was previously reported that n-hexadecanoic acid (palmitic acid) demonstrated the ability to inhibit bacterial biofilm development and reduce quorum sensing mediated gene expression in $V$. harveyi (Santhakumari et. al. 2017). The antioxidants 2,6-di-tert-butyl-4-methylphenol (butylated hydroxytoluene) (Jiang et. al. 2013) and 2,2'-Methylenebis (6-tert-butyl-4-methylphenol) (Jang et. al. 2017) are known for their antiviral and anticarcinogenic properties. Lupeol is a pharmacologically active pentacyclic triterpenoid (Margareth et. al. 2009). It has anti-cancer and anti-inflammatory activity and slightly antimicrobial activities. It is important to note that lupeol has been shown to inhibit the violacein production of $C$. violaceum (Bodede et. al. 2018). The triterpenoid friedelan-3-one has been reported to exhibit antioxidant and antiinflammatory activities (Christudas et. al. 2013) derived from the leaf of Pterocarpus santalinoides showed antibacterial activity (Ichiko et. al. 2016). Then docked in CviR, the higher scores were calculated for 2,2'-methylenebis(4-methyl-6-tert-butylphenol) and 1-(5-(hydroxymethyl)-2,2-dimethyl-1,3-dioxolan-4yl)propan-2-ol. It is better cores than for the known antagonist chlorolactone. Interaction modeling with Cvil demonstrated the best docking scores for gamma-Sitosterol and 2,2'-Methylenebis(4-methyl-6-tertbutylphenol) compared to other tested compounds.

Thus, we determined that oak bark hydro-ethanol extract is a plant material that quite effectively inhibits quorum sensing mediated virulence and soft-rot symptoms caused by $P$. carotovorum, ant these effects can be achieved because of a number of secondary metabolites possess a combined or complementary action, and thereby, makes it possible to be a biopesticide. Molecular modelling has shown that a number of molecules can be incorporated into the active centre of both the CviR receptor protein and the Cvil protein, which possibly determines their quorum quenching properties. Thus, a combination of such molecules well be used as in a plant protection agent against Pectobacterium spp.

\section{Declarations}

Acknowledgements: This work was supported by the Russian Science Foundation (Grant No. 19-7630005) in sections devoted to 3.2 - 3.4. The work was performed within the state assignment of the Ministry of Science and Higher Education of the Russian Federation for 2020-2024 (no. FEWZ-20200006) in sections devoted to 3.1, 3.4 - 3.6.

Bioluminescence E.coli MG 1655 strains were kindly provided by Prof. Ilya V. Manukhov (GosNII Genetica, Moscow). Chromobacterium violaceum strains were kindly provided by Prof. Dmitry G. Deryabin (Federal Scientific Center for Biological Systems and Agricultural Technologies, RAS, Orenburg).

Conflict of interest: no conflict of interest declared

Author contributions: ASV conceived and designed the study. DVP, AVI, RS, AVV, EAR performed the experiments. ASV, DVP, RS, AVV, EAR analyzed and interpreted the data. ASV, EAR drafted and wrote the manuscript. ASV supervised the study. All authors approved the final version of the manuscript. 


\section{References}

1. Adonizio AL, Downum K, Bennett BC, Mathee K (2006) Anti-quorum sensing activity of medicinal plants in southern Florida. J Ethnopharmacol 105:427-435. DOI: 10.1016/j.jep.2005.11.025

2. Assessment report on Quercus robur L., Quercus petraea (Matt.) Liebl., Quercus pubescens Willd., cortex EMA/HMPC/3206/2009. Assessed on may 2021 at https://theodora.com/drugs/eu/quercus_cortex_herbal.html

3. Bodede O, Shaik S, Chenia H, Singh P, Moodley R (2018) Quorum sensing inhibitory potential and in silico molecular docking of flavonoids and novel terpenoids from Senegalia nigrescens. J Ethnopharmacol 216:134-146. doi: 10.1016/j.jep.2018.01.031

4. Chatterjee A, Cui Y, Hasegawa H, Leigh N, Dixit V, Chatterjee AK (2005) Comparative analysis of two classes of quorum-sensing signaling systems that control production of extracellular proteins and secondary metabolites in Erwinia carotovora subspecies. J Bacteriol 187:8026-8038

5. Chen G, Swem LR, Swem DL, Stauff DL, Loughlin CT, Jeffrey PD, Bassler BL, Hughson FM (2011) A strategy for antagonizing quorum sensing. Mol Cell 22(2):199-209 PMID: 21504831; PMCID: PMC3092643

6. Christudas Sunil V, Duraipandiyan S, Ignacimuthu NA, Al-Dhabi Antioxidant, free radical scavenging and liver protective effects of friedelin isolated from Azima tetracantha Lam. leaves, Food Chemistry,Volume 139, Issues 1-4,2013, Pages860-865

7. Chung J, Goo E, Yu S, Choi O, Lee J, Kim J, Kim H, Igarashi J, Suga H, Moon JS, Hwang I, Rhee S (2011) Small-molecule inhibitor binding to an N-acyl-homoserine lactone synthase. Proc Natl Acad Sci U S A. 19; 108(29):12089-94. doi: 10.1073/pnas.1103165108

8. Deryabin D, Galadzhieva A, Kosyan D, Duskaev G (2019) Plant-Derived Inhibitors of AHL-Mediated Quorum Sensing in Bacteria: Modes of Action. Int J Mol Sci 20(22):5588. https://doi.org/10.3390/ijms20225588

9. Deryabin DG, Tolmacheva AA (2015) Antibacterial and Anti-Quorum Sensing Molecular Composition Derived from Quercus cortex (Oak bark) Extract. Molecules 20:17093-17108. https://doi.org/10.3390/molecules200917093

10. Dow JM, Davies HA, Daniels MJ (1998) A metalloprotease from Xanthomonas campestris that specifically degrades proline/hydroxyproline-rich glycoproteins of the plant extracellular matrix. Mol Plant Microbe Interact 11(11):1085-1093

11. Ek-Ramos MJ, Gomez-Flores R, Orozco-Flores AA, Rodríguez-Padilla C, González-Ochoa G, TamezGuerra P (2019) Bioactive Products From Plant-Endophytic Gram-Positive Bacteria. Front Microbiol 10:463. doi: 10.3389/fmicb.2019.00463

12. Fuqua WC, Winans SC, Greenberg EP (1994) Quorum sensing in bacteria: the LuxR-LuxI family of cell density-responsive transcriptional regulators. J Bacteriol 176(2): 269 - 75. doi:

10.1128/jb.176.2.269-275.1994. PMID: 8288518; PMCID: PMC205046 
13. Glare T, Caradus J, Gelernter W, Jackson T, Keyhani N, Köhl J, Marrone P, Morin L, Stewart A (2012) Have biopesticides come of age? Trends in Biotechnology. Is 30(5):250-258

14. Gorshkov V (2017) Plant bacterioses: molecular basis for the formation of plant-microbial pathosystems [in russian], Kazan: Publishing house Sergei Buzukin 304

15. Gur-Arie L, Eitan-Wexler M, Weinberger N, Rosenshine I, Livnah O (2020) The bacterial metalloprotease NleD selectively cleaves mitogen-activated protein kinases that have high flexibility in their activation loop. J Biol Chem 295(28):9409-9420. doi: 10.1074/jbc.RA120.013590

16. Grandclément $C$, Tannières $M$, Moréra $S$, Dessaux $Y$, Faure $D$ (2016) Quorum quenching: role in nature and applied developments, FEMS Microbiology Reviews, Vol 40, Is 1: 86-116. https://doi.org/10.1093/femsre/fuv038

17. Gutiérrez-Pacheco MM, Bernal-Mercado AT, Vázquez-Armenta FJ, Martínez-Tellez MA, GonzálezAguilar GA, Lizardi-Mendoza J, Madera-Santana TJ, Nazzaro F, Ayala-Zavala JF (2019) Quorum sensing interruption as a tool to control virulence of plant pathogenic bacteria. Physiol Mol Plant Pathol 106:281-291. https://doi.org/10.1016/j.pmpp.2019.04.002

18. Husain FM, Ahmad I, Al-thubiani AS, Abulreesh HH, AlHazza IM, Aqil F (2017) Leaf Extracts of Mangifera indica L. Inhibit Quorum Sensing - Regulated Production of Virulence Factors and Biofilm in Test Bacteria. Front Microbiol 8:727. doi: 10.3389/fmicb.2017.00727

19. Ichiko CO, Terrumun ATA, John Ol, John VA (2016) In vitro antimicrobial properties of friedelan-3-one from Pterocarpus santalinoides LHerit, ex Dc. Afr J Biotechnol 15(14):531-538. 10.5897/ajb2015.15091

20. Janak J, Khazanov N, Charkowski A, Faigenboim A, Senderowitz H, Yedidia I (2021) Interkingdom Signaling Interference: The Effect of Plant-Derived Small Molecules on Quorum Sensing in PlantPathogenic Bacteria. Annu Rev Phytopathol. 10.1146/annurev-phyto-020620-095740

21. Janak J, Khazanov N, Khadka N, Charkowski A, Burdman S, Carmi N, Yedidia I, Senderowitz H (2020) Direct Binding of Salicylic Acid to PectobacteriumN-Acyl-Homoserine Lactone Synthase. ACS Chem Biology XXXX. 10.1021/acschembio.0c00185

22. Jang M, Kim H, Park R, Jo D, Lee E, Keun OhW, Park J (2017) 2,2'-Methylenebis (6-tert-butyl 4methylphenol) enhances the antitumor efficacy of belotecan, a derivative of camptothecin, by inducing autophagy. Oncotarget 8:115068-115078

23. Han JH, Paul D, Lee SW, Park JW, Kyung Seok Park (2014) Aqueous Plant Extracts as Possible Quorum Sensing Inhibitory (QSI) Agents against Soft Rot caused by Pectobacterium carotovorum in Tobacco. Pure Appl Microbiol 8(1):63-68

24. Jiang G, Lin S, Wen L, Jiang Y, Zhao M, Chen F, Prasad KN, Duan X, Yang B (2013) Identification of a novel phenolic compound in litchi (Litchi chinensis Sonn.) pericarp and bioactivity evaluation. Food Chem 136(2):563-568

25. Joshi JR, Khazanov N, Senderowitz H, Burdman S, Lipsky A, Yedidia I (2016) Plant phenolic volatiles inhibit quorum sensing in pectobacteria and reduce their virulence by potential binding to Expl and ExpR proteins. Sci Rep 6:38126. doi: 10.1038/srep38126. PMID: 27905512; PMCID: PMC5131480 
26. Joshi JR, Khazanov N, Senderowitz H, Burdman S, Lipsky A, Yedidia I (2016) Plant phenolic volatiles inhibit quorum sensing in pectobacteria and reduce their virulence by potential binding to Expl and ExpR proteins. Sci Rep 6:38126. doi: 10.1038/srep38126. PMID: 27905512; PMCID: PMC5131480

27. Koh CL, Sam CK, Yin WF, Tan LY, Krishnan T, Chong YM, Chan KG (2013) Plant-derived natural products as sources of anti-quorum sensing compounds. Sens (Basel) 13(5):6217-6228. doi: 10.3390/s130506217. PMID: 23669710; PMCID: PMC3690052

28. Kotova VY, Manukhov IV, Zavilgelskii GB (2010) Lux-biosensors for detection of SOS-response, heat shock, and oxidative stress. Appl Biochem Microbiol 46:781-788. https://doi.org/10.1134/S0003683810080089

29. Leadbeater AJ (2014) Plant Health Management: Fungicides and Antibiotics.Encyclopedia of Agriculture and Food Systems408-424

30. Mansfield J, Genin S, Magori S, Citovsky V, Sriariyanum M, Ronald P, Dow M, Verdier V, Beer SV, Machado MA, Toth I, Salmond G, Foster GD (2012) Top 10 plant pathogenic bacteria in molecular plant pathology. Mol Plant Pathol 13:614-629. https://doi.org/10.1111/j.1364-3703.2012.00804.x

31. Manukhov IV, Khrul'nova SA, Baranova A, Zavilgelsky GB (2011) Comparative Analysis of the Lux Operons In Aliivibrio Logei Kch1 (a Kamchatka Isolate) and Aliivibrio Salmonicida. J Bacteriol 193:3998-4001

32. Margareth BC (2009) Gallo, bullet Miranda,J Sarachine. Biological Activities of Lupeol. International Journal of Research in Pharmaceutical and Biomedical Sciences, 3 (special issue 1):46-66

33. Pitt TL, Dey D (1970) A Method for the Detection of Gelatinase Production by Bacteria. J Appl Bacteriol 33:687-691. https://doi.org/10.1111/j.1365-2672.1970.tb02251.x

34. Põllumaa L, Alamäe T, Mäe A (2012) Quorum Sensing and Expression of Virulence in Pectobacteria. Sens (Basel) 12(3):3327-3349

35. Pratima G, Kalpana S, Avinash S (2012) Isolation of Cellulose-Degrading Bacteria and Determination of Their Cellulolytic Potential International Journal of Microbiology |Article ID 578925 |. https://doi.org/10.1155/2012/578925

36. Pun M, Khazanov N, Galsurker O, Weitman M, Kerem Z, Senderowitz H, Yedidia I (2021) Phloretin, an Apple Phytoalexin, Affects the Virulence and Fitness of Pectobacterium brasiliense by Interfering With Quorum-Sensing. Front Plant Sci 12:671807. doi: 10.3389/fpls.2021.671807

37. Santhakumari S, Nilofernisha NM, Ponraj JG, Pandian SK, Ravi AV (2017) In vitro and in vivo exploration of palmitic acid from Synechococcus elongatus as an antibiofilm agent on the survival of Artemia franciscana against virulent vibrios. J Invertebr Pathol 150:21-31. DOI: 10.1016/j.jip.2017.09.001

38. Savidor A, Teper D, Gartemann KH, Eichenlaub R, Chalupowicz L, Manulis-Sasson S, Barash I, Tews H, Mayer K, Giannone RJ, Hettich RL, Sessa G (2012) The Clavibacter michiganensis subsp. michiganensis-tomato interactome reveals the perception of pathogen by the host and suggests mechanisms of infection. J Proteome Res 11(2):736-750. doi: 10.1021/pr200646a 
39. Singh AA, Singh AK, Nerurkar A (2021) Disrupting the quorum sensing mediated virulence in soft rot causing Pectobacterium carotovorum by marine sponge associated Bacillus sp. OA10. World J Microbiol Biotechnol 37:5. https://doi.org/10.1007/s11274-020-02982-4

40. Sundin GW, Castiblanco LF, Yuan X, Zeng Q, Yang C-H (2016) Bacterial disease management: challenges, experience, innovation and future prospects. Mol Plant Pathol 17:1506-1518

41. Tolmacheva AA, Rogozhin EA, Deryabin DG (2014) Antibacterial and quorum sensing regulatory activities of some traditional Eastern-European medicinal plants. Acta Pharm 64(2):173-186. https://doi.org/10.2478/acph-2014-0019

42. Travis Glare J, Caradus W, Gelernter T, Jackson N, Keyhani (2012) Jürgen Köhl, Pamela Marrone, Louise Morin, Alison Stewart. Have biopesticides come of age? Trends in Biotechnology. 30:2502585

\section{Tables}

Table 1. The phytochemicals identified in the Quercus cortex extract by gas chromatography-mass spectrometry 


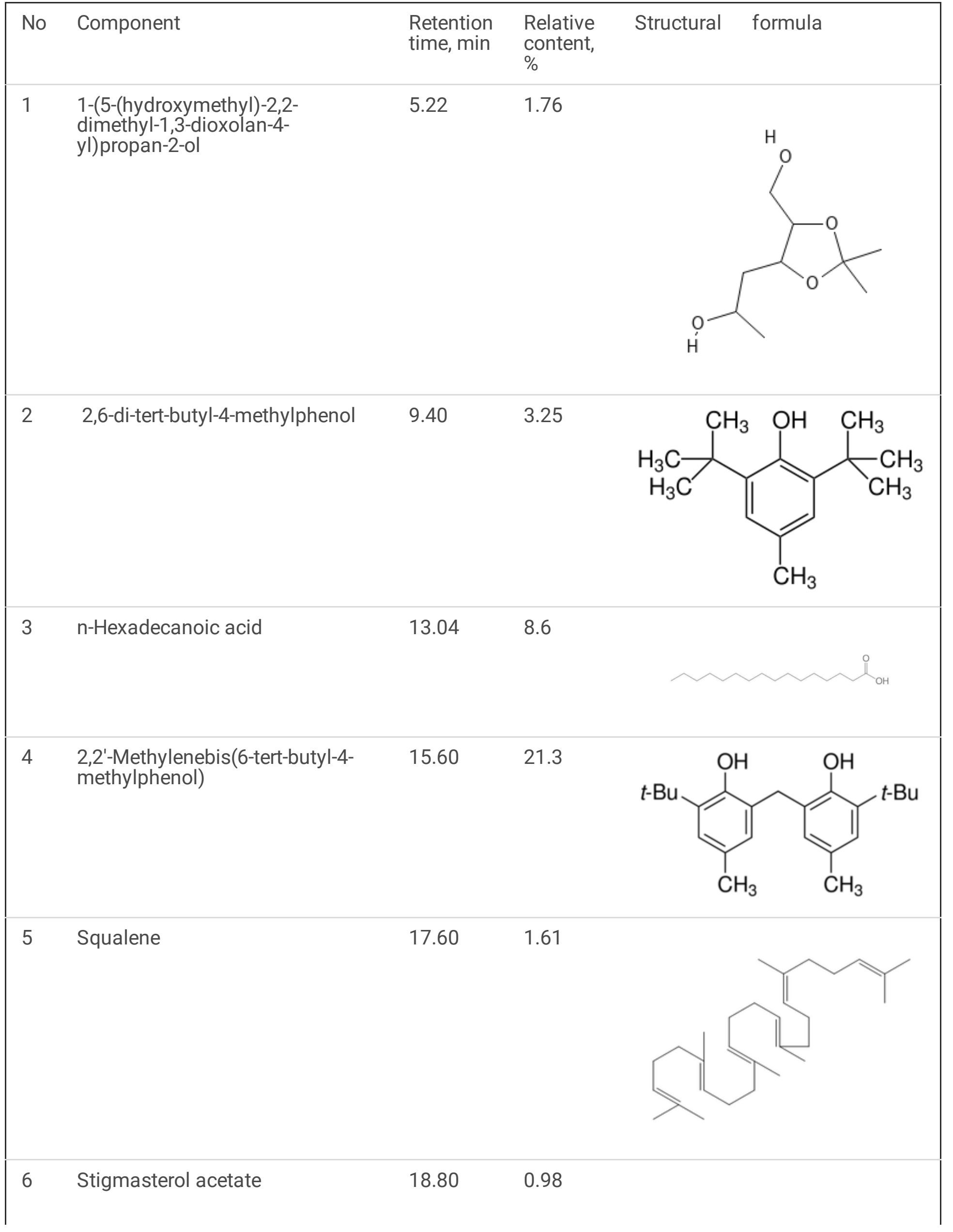




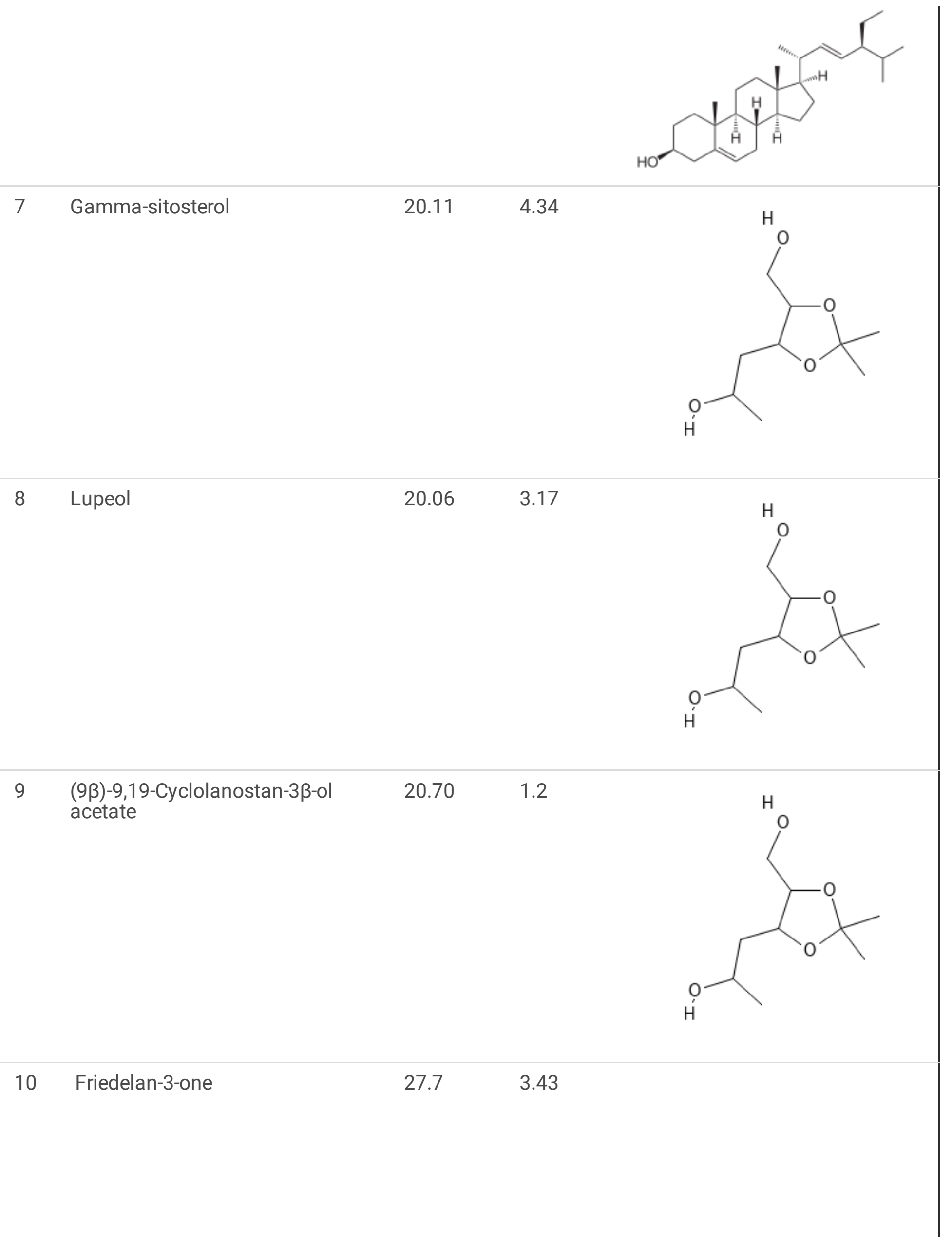




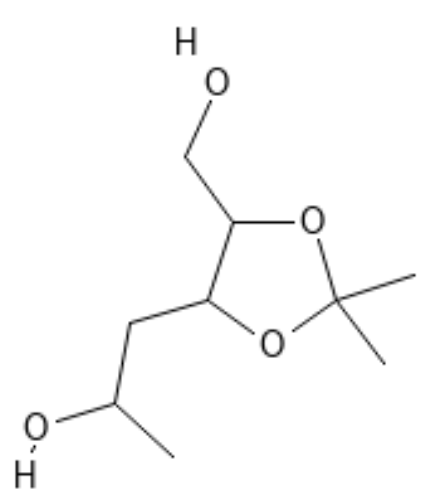

Table 2. Docking results of complexes from Cvil and CviR proteins. 


\begin{tabular}{|ll|}
\hline CviR / Ligand & Docking score (kcal mol ${ }^{-1}$ ) \\
\hline 2,2'-Methylenebis(4-methyl-6-tert-butylphenol) & -7.876 \\
\hline 1-(5-(hydroxymethyl)-2,2-dimethyl-1,3-dioxolan-4-yl)propan-2-ol & -7.739 \\
\hline (9ß)-9,19-Cyclolanostan-3ß-ol acetate (-6.364 kcal/mol) & -7.540 \\
\hline Butylated hydroxytoluene & -7.397 \\
\hline Chlorolactone & -7.222 \\
\hline (resolved in the crystal structure, re-docked) & \\
\hline gamma-Sitosterol & -6.555 \\
\hline [5-(Hydroxymethyl)-2,2-dimethyl-1,3-dioxolan-4-yl]methanol & -5.675 \\
\hline Hexadecanoic acid & -5.485 \\
\hline Squalene & -4.751 \\
\hline Friedelan-3-one & -3.221 \\
\hline Cvil / Ligand & \\
\hline 5'-Deoxy-5'-methylthioadenosine & -7.553 \\
\hline (resolved in the crystal structure, re-docked) & \\
\hline gamma-Sitosterol & -6.888 \\
\hline (9ß)-9,19-Cyclolanostan-3ß-ol acetate (-6.364 kcal/mol) & -6.364 \\
\hline 1-(5-(hydroxymethyl)-2,2-dimethyl-1,3-dioxolan-4-yl)propan-2-ol & -6.296 \\
\hline 2,2'-Methylenebis(4-methyl-6-tert-butylphenol) & -5.835 \\
\hline Lupeol & -4.497 \\
\hline Butylated hydroxytoluene & -4.438 \\
\hline Squalene & -2.538 \\
\hline Stigmasterol acetate & -2.468 \\
\hline Friedelan-3-one & -438 \\
\hline
\end{tabular}

Target: Chromobacterium violaceum CviR transcriptional regulator (PDB ID: 3QP5); and Chromobacterium violaceum Cvil acyl-homoserine-lactone synthase homology model built on Tofl from Burkholderia glumae structure (PDB ID: 3P2H).

\section{Figures}




\section{Figure 1}

C6-oxo-HSL autoinducers synthesis by $P$. carotovorum VKM-B-1247 and its perception by C.violaceum CV026, when growing on medium with the addition of oak bark extract for 0 (a), 0.25 (b), 0.5 (c), and 1.0 $\mathrm{mg} / \mathrm{mL}(\mathrm{d})$.

\section{Figure 2}

The bioluminescent response of the E. colipVFR1-lux sensor is proportional to the amount of C6-oxo-HSL contained in the $P$. carotovorum VKM B-1247 culture medium. Each bar represents three replicates, from two independent experiments. Treatments not connected by the same letter in each panel are significantly different from each other $(p<0.05$; means $\pm S D)$.

\section{Figure 3}

Effects of oak bark extract on the transcript levels of quorum sensing (QS) system genes in $P$. carotovorum VKM-B-1247. The transcript levels of the QS system genes expl, expR were determined by quantitative real time-polymerase chain reaction (qRT-PCR) of cDNA samples prepared from RNA extracts of bacterial cultures grown in LB-Broth with or without (control) the oak bark extract. Treatments not connected by the same letter in each panel are significantly different from each other $(p<0.05$; means \pm $\mathrm{SD})$.

\section{Figure 4}

Oak bark extract reduces exoenzyme activities of $P$. carotovorum VKM-B-1247. Enzymatic activity was estimated on the size of substrate degradation haloes during $24 \mathrm{~h}$ cell growth on agar medium without the addition (intact) and with the addition of oak bark extract at concentrations of $0.5-1.0 \mathrm{mg} / \mathrm{mL}$ (a). Results are expressed as the percentage of activity relative to controls without the compounds. Treatments not connected by the same letter in each panel are significantly different from each other $(p<$ 0.05 ; means \pm SD) (b). 


\section{Figure 5}

Inhibition of $P$. carotovorum virulence on potatoes. Potato discs coated with oak bark extract $(1 \mathrm{mg} / \mathrm{mL})$ before bacteria were inoculated $\left(10^{6} \mathrm{CFU} / \mathrm{ml}\right)$. Representative photos of development of soft-rot symptoms on untreated (a-c) and pretreated with OBE (d-f). Photos were made at $24(\mathrm{a}, \mathrm{d}), 48(\mathrm{~b}, \mathrm{e})$, and 72 hours $(c, f)$. Plant-protection effect was determined as the percentage of macerated tissue $72 \mathrm{~h}$ after the inoculation of potato tubers with P.carotovorum (g). Treatments not connected by the same letter in each panel are significantly different from each other $(p<0.05$; means \pm SD).

\section{Figure 6}

Docked complex of Cvil from Chromobacterium violaceum homology model built on Tof I from Burkholderia glumae (PDB ID: 3P2H). Complex Cvil with endogenous ligand 5'-Deoxy-5'-

methylthioadenosine (a) and gamma-sitosterol (b).

Docked complex of the CviR transcriptional regulator from Chromobacterium violaceum (PDB ID: 3QP5) with native antagonist chlorolactone (c), and 2,2-Methylenebis(4-methyl-6-tert-butylphenol) (d). Only key amino acids of proteins are shown for clarity. Ligands are shown as grey sticks, hydrogen bonds as yellow lines, and pi-pi stacking interactions as blue lines.

\section{Supplementary Files}

This is a list of supplementary files associated with this preprint. Click to download.

- Supplementaryfiles.docx 